\title{
Statistical comparison of the external validity (positive predictive value and negative predictive value) of three anthropometric indices used in the diagnosis of pathological nutritional situations overweight and obesity
}

DOI: $10.46932 / \mathrm{sfjdv} 2 \mathrm{n} 1-050$

Received in: November 1st, 2020

Accepted in: December 30th, 2020

\author{
José Franco-Monsreal \\ Doctor en Ciencias Médicas \\ E-mail: jose.franco@uimqroo.edu.mx \\ Juan Pablo Ku-Tuz \\ Licenciado en Salud Comunitaria \\ E-mail: juan.ku@uimqroo.edu.mx;
}

\author{
Lidia Esther del Socorro Serralta-Peraza \\ Maestra en Educación \\ E-mail: lidia.serralta@uimqroo.edu.mx \\ María Selene Sánchez-Uluac \\ Maestra en Ciencias \\ E-mail: biosele@hotmail.com
}

\begin{abstract}
To compare the external validity (positive predictive value and negative predictive value) of the Body Mass Index versus the external validity of the Waist/Hip Index versus the external validity of the Abdominal Circumference as diagnostic methods indicating overweight and obesity in adult patients aged 18-64 years of age of both genders who attended the Integral Hospital "Jose Maria Morelos" of the Mayan municipality of Jose Maria Morelos, Quintana Roo, Mexico, in the period from August 1, 2017 to July 31, 2018. The study design corresponds to that of a descriptive observational epidemiological study without directionality and with prospective temporality. The study was carried out in a population consisting of 300 adult patients [119 (39.67\%) of the male gender and $181(60.33 \%)$ of the female gender]. The Miller et al. Equation, which provides the ideal body weight for both genders, was used as a reference test or Gold Standard. Using this equation, 171 (57.00\%) and $129(43.00 \%)$ observation units were labeled with and without overweight and obesity, respectively. In ascending numerical order, the observed positive predictive values were 68.32\% (138/202) for Abdominal Circumference; $69.49 \%$ (123/177) for the Waist/Hip Ratio; and 70.85\% (141/199) for the Body Mass Index. Regarding the negative predictive values observed, in ascending numerical order, they were $60.98 \%(75 / 123)$ for the Waist/Hip Index; 66.33\% (65/98) for the Abdominal Circumference; and 70.30\% (71/101) for the Body Mass Index. The diagnostic test with the highest positive predictive value and the highest negative predictive value was the Body Mass Index.
\end{abstract}

Keywords. External validity, anthropometric indices, overweight and obesity. 


\section{INTRODUCTION}

Overweight and obesity are defined as an abnormal or excessive accumulation of fat that can be detrimental to health. The Body Mass Index (BMI) is a simple indicator of the relationship between weight and height that is frequently used to identify overweight and obesity in adults. It is calculated by dividing a person's weight in $\mathrm{kg}$ by the square of their height in $\mathrm{m}\left(\mathrm{kg} / \mathrm{m}^{2}\right)$. For adults, the World Health Organization (WHO) defines overweight, and obesity as follows: 1 . Overweight: BMI $\geq 25.00 \mathrm{~kg} / \mathrm{m}^{2}$; and 2. Obesity: $\mathrm{BMI} \geq 30.00 \mathrm{~kg} / \mathrm{m}^{2}$. BMI provides the most useful measure of overweight and obesity in the population, since it is the same for both genders and for adults of all ages. However, it must be considered as an approximate value because it may not correspond to the same level of thickness in different people (https://www.who.int/es/news-room/fact-sheets/detail/obesity-and-overweight).

According to the WHO, obesity is growing alarmingly, since today it is estimated that more than 250 million people are obese in the world, that is, $7 \%$ of the adult population. Obesity is defined as a generally chronic multifactorial pathological entity manifested by a condition of excess body fat associated with many chronic-degenerative conditions and life disorders, most of which are treatable (WHO 2014).

The prevalence of overweight and obesity has increased worldwide in the last three decades, affecting two out of every three adults in 2014 (Collaboration NCDRF, Stevens et al. 2012).

Mexico has been one of the countries with the highest prevalence of obesity in the last two decades and some of its comorbidities currently occupy the first places of mortality (Barquera et al. 2013).

Although the distribution of overweight and obesity is relatively homogeneous throughout the national territory, the prevalences in the school and adolescent population tend to be higher in the northern region. In adults, Mexico City has slightly higher prevalences than the rest of the country and, in general terms, both conditions are more prevalent in urban populations than in rural ones (Shamah et al. 2007).

Because of the high number of people who suffer from it, because of the risk that it implies in the biological, psychological and social spheres in the individual, as well as because of the physical disability that it causes leads to an increased risk of premature death in a high percentage; it also generates significant economic losses (González \& Stern 2013).

Except for people who are very muscular, those whose weight exceeds at least $20 \%$ the midpoint of the weight scale according to the standard weight/height value are considered obese. Obesity can be classified as mild (overweight between 20\%-40\%), moderate (overweight between 41\%-100\%) and severe (overweight $\geq 101 \%$ ) (González et al. 2010).

Obesity, by itself, is one of the most frequent metabolic disorders in medical practice and among the most frustrating and difficult to treat. Furthermore, it is a frequent cause of morbidity and mortality. 
Even though in the last 25 years some progress has been made in the treatment of obesity, nevertheless, there have been important changes in the knowledge of its causes and health implications (Casillas \& Vargas 2013).

Obesity is defined as a pathological entity of multifactorial origin that produces multiple complications, which is associated with practically all chronic-degenerative diseases, characterized by excess energy deposits in the form of body fat, which has adverse effects on the health and longevity due to its association, among many other problems, with arterial hypertension, lipoproteinemia, type 2 diabetes mellitus, gallstones, osteoarthritis and certain types of cancer; total body fat should not be greater than 10-20\% in men and 20-30\% in women (Alberti et al. 2015).

Obesity is accepted as excess body fat based on measurements of adipose tissue; the prevalence of obesity increases in the world in both children and adults, reaching between 20 and 50\%, with women being the most affected with 1.7 for every obese man; it is the most frequent and important nutritional disease in the world. It has been estimated that in the United States of North America it affects about $40 \%$ of the adult population, in Great Britain one third to half of its population is affected and developing countries of the Caribbean and South America are having serious increases in obesity. Due to its frequency, in Mexico it constitutes a public health problem. Statistics reveal that $35 \%$ of the population is obese, particularly in the female gender, and $60 \%$ is overweight, especially in the male gender; however, simplistic appraisals reduce a problem with deeper roots to mere outward appearance; in rural areas the frequency is $4-10 \%$, in suburban areas $12 \%$ and in urban areas 35\% with a ratio of 1.4 women : 1 man. Based on current trends, obesity is forecast to continue to be a public health problem with a marked increase; recently, the WHO established a twofold growth in the number of severely overweight adults compared to those who are underweight between 1995 and 2025 (WHO 1998). Raw projections, extrapolating existing data, suggest that by 2025 obesity levels will be between $45-55 \%$ in the United States of America; between 30-40\% in Australia, England and India; and over 20\% in Brazil (Alberti et al. 2015).

In Mexico, the prevalences of overweight and obesity have increased in recent years. From 1980 to date, these have tripled and, at present, just over $70 \%$ of the Mexican adult population has a weight above what is recommended. This is mainly due to a higher consumption of energy-dense foods and less physical activity; excess weight is one of the main risk factors for the development of chronic noncommunicable diseases such as diabetes mellitus, high blood pressure, and cardiovascular diseases. Although the distribution of overweight and obesity is relatively homogeneous throughout the national territory, the prevalences in the school and adolescent population tend to be higher in the northern region. 
In adults, Mexico City has slightly higher prevalences than the rest of the country and, in general terms, both conditions are more prevalent in urban populations than in rural ones (Shamah-Levy et al. 2007).

In older age groups, the lower frequency of obesity reflects the higher mortality at younger ages associated with obesity-related diseases. Likewise, the prevalence of obesity varies with the socioeconomic level (even poverty is associated with great obesity, especially in the female gender) and with culture, since they exert important influences (Frenk 2004).

Body fat fulfills many functions, among which the preservation of heat, the protection of target organs and being a constituent of the body's cells stand out; fat is only harmful when it exists in excess in the body, in general and particularly at the intra-abdominal and periportal level. Until recently it was the direct result of a sedentary life coupled with a chronic ingestion of kilocalories (Kcal) that causes an imbalance between the energy that is ingested and the energy that is used. Although there is no doubt that these factors are the main cause, today it has been proven that many other factors participate in its etiology; increased deposits of adipose tissue are found in subcutaneous tissue, around internal organs, in the momentum, and in intramuscular spaces, with greater amounts of lean body mass, as evidenced by a greater increase in kidneys, heart, liver, and skeletal muscle mass up to hepatic steatosis (fatty liver); it has been shown that the increase in adipose tissue only exists during a limited period of early childhood and perhaps during puberty; therefore, before reaching adulthood, the probability of an increase in the number of adipocytes decreases. From this moment on, the expansion of the adipose mass is mainly achieved by the increase in the size of the fat cells (Altman \& Bland 2014).

There is a genetic or hereditary background that includes several genes (such as leptin, a satiety protein produced only in adipose tissue) that intervene in the regulation of energy that causes greater metabolic efficiency so that it cannot be dissipated in the form of heat; once obesity occurs, a decrease in physical activity is also important, which contributes to facilitating weight gain and a psychological image of fat maintenance (Grimes \& Schultz 2015).

The main complications that increase morbidity and mortality according to the degree of obesity are: increase in general mortality; increased cardiovascular mortality (coronary artery disease and atherosclerosis); arterial hypertension; dyslipoproteinemias; hyperglycemia; hyperinsulinemia or insulin resistance; metabolic syndrome; adult apnea syndrome; decreased testosterone and increased estrogen and estradiol; increased frequency of cholelithiasis; arthrosis of the joints; difficulties for social, physical, labor and economic relationships; venous circulation disorders; increased incidence in certain neoplasms (endometrium, breast, bile ducts and ovary in women; colon, rectum and prostate in men); drop; reduced fertility; cerebral vascular disease; skin disorders; and increased risk in surgical and obstetric acts (Grimes \& Schultz 2012). 
According to its etiology, obesity is classified as: 1. Essential obesity; and 2. Secondary obesity; essential obesity is the most common and constitutes more than $95 \%$ of cases of clinical obesity; it results from a complex interaction of environmental factors (poor diet, sedentary habits, psychological factors and sociocultural factors) associated with genetic predisposition. When the intake of Kcal exceeds the expenditure, the excess of Kcal is deposited in the adipose tissue and if this positive balance is maintained there is obesity; normal daily caloric needs range from 26-33 Kcal (110-139 KJ) per kg of body weight; the figure is higher in people who perform physical activities and lower in sedentary people (Fernandez \& Diaz 2013).

According to the distribution of body fat measured by the Waist/Hip Index (ICC), obesity is classified as: 1. Android; and 2. Gynecoid. Android obesity, or predominantly in the upper body segment, is a risk factor for the development of arterial hypertension, glucose intolerance, type 2 diabetes mellitus, hyperlipidemia and arterial damage; gynecoid obesity, to date, is considered a minor cardiovascular risk factor (Harper \& Reeves 2011).

Since there is no infallible value that diagnoses overweight and obesity, several methods must be used in a complementary way to have a more complete and reliable clinical approach. Currently, various techniques are used to measure body fat such as Computed Axial Tomography and Nuclear Magnetic Resonance, which are useful to determine intra-abdominal and subcutaneous fat and are correlated with the ICC that is used as an indicator of fat distribution; however, they entail great cost and experience of the medical staff; other methods are the measurements of the skin folds (subscapularis, biceps and suprailiac, among others) that also entail great experience and precision for their realization and determination and are highly variable between individuals (Mataix-Verdú 2013).

The present work aimed to statistically compare the external validity (positive predictive value and negative predictive value) of the BMI versus the external validity of the ICC versus the external validity of the Abdominal Circumference (AC) as diagnostic methods indicating overweight and obesity in patients adults aged 18-64 years of both genders who attended the Integral Hospital "Jose Maria Morelos" of the Mayan municipality of Jose Maria Morelos, Quintana Roo, Mexico, in the period from August 1, 2017 to July 31, 2018.

Null hypothesis $\left(\mathrm{H}_{0}\right)$. There is no statistically significant evidence at the significance level or significance level $(\alpha)$ of $5 \%$ to conclude that the two components of the external validity of the BMI versus the two components of the external validity of the ICC versus the two components of the external validity of the AC are different.

Alternative hypothesis $\left(\mathrm{H}_{1}\right)$. There is statistically significant evidence at the significance level or significance level $(\alpha)$ of $5 \%$ to conclude that the two components of the external validity of the BMI versus 
the two components of the external validity of the ICC versus the two components of the external validity of the AC are different.

BMI. Of routine use for quantitative evaluation it reflects, with greater precision, the excess of adipose tissue; however, it is altered in the case of high muscle mass and edema and probably varies with age. It is calculated by dividing the weight (in $\mathrm{kg}$ ) by the square of the height (in $\mathrm{m}$ ) and is expressed in $\mathrm{kg} / \mathrm{m}^{2}$. An especially important aspect of obesity is the distribution of body fat, since the central or abdominal location is associated with a high risk of cardiovascular complications, dyslipidemia, insulin resistance, arterial hypertension, type 2 diabetes mellitus and metabolic syndrome; also, in moderate obesity the android silhouette predominates but, in severe obesity, the index has little value, since fat accumulates throughout the body. The importance of central obesity is clear in some populations (Asia) where the BMI is relatively low; however, abdominal fat rates are high and present the complications mentioned. A recent study carried out in India revealed that $20 \%$ of adults who are neither obese nor overweight have, however, central obesity and are at high risk of developing the above complications. Therefore, there are abdominal measurement indices that, carried out correctly, reflect cardiovascular risk and chronic disease risk and that, together with BMI, allow the identification of high-risk health biases; in the same way, it is especially important to identify the gender; in adults. WHO, in 2014, defined overweight and obesity as follows: 1 . Overweight: $25.00 \mathrm{~kg} / \mathrm{m}^{2} \leq \mathrm{BMI} \leq 29.99 \mathrm{~kg} / \mathrm{m}^{2}$; and 2. Obesity: $\mathrm{BMI} \geq 30.00 \mathrm{~kg} / \mathrm{m}^{2}$ (WHO 2014).

ICC. The ICC is a specific anthropometric measure to measure intra-abdominal fat levels; mathematically, it is the quotient obtained by dividing the perimeter of the waist by the perimeter of the hips. There are two types of obesity according to the pattern of body fat distribution: 1. Android; and 2. Gynecoid. The first type is called intra-abdominal or visceral obesity and the second extra-abdominal or subcutaneous obesity and to quantify it, it has been seen that an anthropometric measure such as the ICC correlates well with the amount of visceral fat, which makes this ratio a feasible measurement from the practical point of view. This measure is complementary to the BMI, since the BMI does not distinguish whether overweight is due to physiological (healthy) muscle hypertrophy, as is the case in athletes, or to an increase in pathological (unhealthy) body fat. WHO establishes normal levels for the ICC of 1.00 units in men and 0.80 units in women; higher values indicate abdominovisceral obesity, which is associated with an increased cardiovascular risk and an increased probability of contracting diseases such as type 2 diabetes mellitus and arterial hypertension. The index is obtained by measuring the perimeter of the waist at the level of the last floating rib and the maximum perimeter of the hip at the level of the buttocks; in adults, overweight and obesity are defined as follows: 1 . Male gender: ICC $\geq 1.01$ units; and 2 . Female gender: ICC $\geq 0.85$ units (WHO 2014). 
AC. The Spanish Heart Foundation (FEC) warns that the area of the body in which fat is accumulated is a more important cardiovascular risk factor than excess weight (overweight or obesity) and, therefore, recommends measuring $\mathrm{AC}$ in instead of calculating only the BMI. Depending on the location of the excess fat, there are two types of obesity: 1. Peripheral (excess fat is located in the buttocks, thighs and arms); and 2. The central one (excess fat is concentrated in the abdomen); the latter is the one with the worst consequences for the body, since various studies have shown that excess abdominal fat can double the risk of cardiovascular disease; the fat accumulated around some of the main organs of the body, called visceral fat, promotes changes in cholesterol, increased triglycerides, increased risk of type 2 diabetes mellitus, increased blood pressure and risk of thrombosis; all these factors favor the development of cardiovascular disease. This accumulation of fat is a consequence of genetic and hormonal factors and of following unhealthy lifestyles such as poor diet, tobacco consumption, sedentary lifestyle and stress, among others; abdominal circumference can be easily measured with a tape measure. The person should stand, with the feet together, the arms at the sides and the abdomen relaxed, then surround the abdomen with the measuring tape at the level of the navel and without pressing, take a deep breath and immediately draw the air; the maximum healthy value of the $\mathrm{AC}$ is $102 \mathrm{~cm}$ in men and $88 \mathrm{~cm}$ in women; in adults, overweight and obesity are defined as follows: 1 . Male gender: $\mathrm{AC} \geq 102 \mathrm{~cm}$; and 2 . Female gender: $\mathrm{AC}$ $\geq 88 \mathrm{~cm}($ WHO 2014).

\section{MATERIAL AND METHODS}

\section{-Epistemological approach}

Quantitative approach, probabilistic approach or positivist approach (Hernández et al. 2014).

\section{-Study design}

Descriptive, cross-sectional epidemiological study with no directionality and prospective temporality (Hernández 2015).

\section{-Study universe}

The study was carried out in a population made up of 300 adult patients [119 (39.67\%) men and $181(60.33 \%)$ women] aged 18-64 years who attended the Integral Hospital "Jose Maria Morelos" in the period between 1 August 2017 to July 31, 2018.

\section{-Operational definitions of the variables}

-IMC. Measure of association between weight (in $\mathrm{kg}$ ) and height (in $\mathrm{m}^{2}$ ) of a person. It was devised by the Belgian statistician Adolphe Lambert Jacques Quetelet (1796-1874), which is why it is also known 
as the Quetelet Index; the BMI responds to the following formula: Weight (in $\mathrm{kg}$ )/Height (in $\mathrm{m}^{2}$ ); Values $\geq 25.00 \mathrm{~kg} / \mathrm{m}^{2}$ are considered abnormal in both men and women (WHO 2014).

-Overweight. $25.00 \mathrm{~kg} / \mathrm{m}^{2} \leq \mathrm{BMI} \leq 29.99 \mathrm{~kg} / \mathrm{m}^{2}$

-Obesity. BMI $\geq 30.00 \mathrm{~kg} / \mathrm{m}^{2}$

-Slight obesity. $30.00 \mathrm{~kg} / \mathrm{m}^{2} \leq \mathrm{BMI} \leq 34.99 \mathrm{~kg} / \mathrm{m}^{2}$

—Moderate obesity. $35.00 \mathrm{~kg} / \mathrm{m}^{2} \leq \mathrm{BMI} \leq 39.99 \mathrm{~kg} / \mathrm{m}^{2}$

-Severe or morbid obesity. $40.00 \mathrm{~kg} / \mathrm{m}^{2} \leq \mathrm{BMI} \leq 49.99 \mathrm{~kg} / \mathrm{m}^{2}$

-Extreme obesity. BMI $\geq 50.00 \mathrm{~kg} / \mathrm{m}^{2}$

-ICC. The ICC is a specific anthropometric measure to measure intra-abdominal fat levels; mathematically, it is a ratio to divide the perimeter of the waist by the perimeter of the hips. In adults, the National Institute of Health defines overweight, and obesity as follows: 1 . Male gender: ICC $\geq 1.01$ units; and 2. Female gender: ICC $\geq 0.85$ units (WHO 2014).

-AC. In adults, the National Institute of Health defines overweight, and obesity as follows: 1. Male gender: $\mathrm{AC} \geq 102 \mathrm{~cm}$; and 2. Female gender: $\mathrm{AC} \geq 88 \mathrm{~cm}$ (WHO 2014).

-Reference test or Gold Standard. It is the best existing diagnostic alternative to study a disease or event of interest in terms of sensitivity, specificity, safety, positive predictive value and negative predictive value; consequently, it is the best option for labeling patients with and without the disease or event of interest (Grimes \& Schulz 2012). As a reference test or Gold Standard, the Miller et al. equation was used, which provides the ideal body weight for both genders: 1 . Male gender: $50.0 \mathrm{~kg}+0.555$ [Height (in cm) - 152.4]; y 2. Female gender: $45.5 \mathrm{~kg}+0.535$ [Height (in $\mathrm{cm}$ ) - 152.4] (Miller et al. 1983).

\section{-Techniques and procedures}

The information was captured in the Clinical Archives Department of the Integral Hospital "Jose Maria Morelos" in the Mayan municipality of Jose Maria Morelos, Quintana Roo, Mexico. The population consisted of 300 adult patients, both men and women, who attended this service during the period from August 1, 2017 to July 31, 2018.

\section{-Data processing}

In the elaboration stage, the data were reviewed (information quality control); classified (on qualitative and quantitative scales); computerized (Minitab software for Windows, version 18 was used); presented (in Tables and Figures); and summarized (the corresponding summary measures were used for data classified in qualitative and quantitative scales). In the analysis and interpretation stages, the data were analyzed and interpreted, respectively.

In the Letter of Ethical Responsibilities, the authors declare that for the performance of the work "Comparative study of the external validity of three anthropometric indices used in the diagnosis of 
overweight and obesity" no experiments were performed on humans or animals; we declare that we follow the protocols of the Universidad Intercultural Maya de Quintana Roo on the publication of patient data; and we declare that no patient data appears in this manuscript.

$2 \times 2$ contingency tables were constructed from which the positive predictive value and the negative predictive value were calculated for each of the three diagnostic tests; the Mantel-Haenszel Chi-Square statistic $\left(\mathrm{x}^{2} \mathrm{M}-\mathrm{H}\right)$ was used as a hypothesis test or a test of statistical significance (Mantel \& Haenszel 1959); Epi lnfo software for Windows, version 7.1.5.2, was used to obtain both the values of the statistic $\mathrm{x}^{2} \mathrm{M}-\mathrm{H}$ and the values of the probabilities $(p)$; there is no method for estimating body composition that has sufficient statistical precision to be considered a reference method against which to validate other methods; for this reason, different methods coexist with various advantages and disadvantages, choosing the researcher the one that best suits his needs (Montalbán-Sánchez 2011); therefore, in the present work the equation of Miller et al. (Miller et al. 1983) was used as a reference test or Gold Standard, which provides the ideal body weight: 1. Male gender: 50.0 kilograms + 0.555 [Height (in $\mathrm{cm})-152.4]$; and 2 . Female gender: 45.5 kilograms +0.535 [Height (in cm) - 152.4]; Using this equation, 171 (57.00\%) and $129(43.00 \%)$ observation units were labeled with and without overweight and obesity, respectively. The criterion applied in performing the hypothesis tests for the difference between two percentages was based on the following recommendations made by Cochran (Cochran 1954): 1 . When $\mathrm{N}>40$ use the $\mathrm{x}^{2}{ }_{\mathrm{M}-\mathrm{H}}$ test; 2. When $20 \leq \mathrm{N} \leq 40$ use the $\mathrm{x}^{2} \mathrm{M}-\mathrm{H}$ test if, and only if, all expected frequencies are $\geq 5$; If in any cell there is at least one expected frequency $<5$, then use Fisher's exact probability test (PPEF); and 3. When $\mathrm{N}<$ 20 use the PPEF.

$$
\begin{gathered}
\mathrm{X}^{2} \mathrm{M} \mathrm{H}=\sum(|\mathrm{O}-\mathrm{E}| 0.5)^{2} / \mathrm{E} ; \mathrm{y} \\
\mathrm{PPEF}=(\mathrm{A}+\mathrm{B}) !(\mathrm{C}+\mathrm{D}) !(\mathrm{A}+\mathrm{C}) !(\mathrm{B}+\mathrm{D}) ! / \mathrm{N} ! \mathrm{A} ! \mathrm{B} ! \mathrm{C} ! \mathrm{D} !
\end{gathered}
$$

\section{RESULTS}

Three hundred patients aged 18-64 years of both genders were studied in the period from August 1, 2017 to July 31, 2018; the absolute and relative frequencies of the 300 observation units were 119 $(39.67 \%)$ and $181(60.33 \%)$ for the male and female genders, respectively. According to the Gold Standard (Miller et al. 1983), 171 (57.00\%) patients were labeled with overweight and obesity and 129 $(43.00 \%)$ patients without overweight and obesity.

Table I shows the absolute and relative frequencies of the 300 patients due to pathological nutritional situations, overweight and obesity according to BMI (in $\mathrm{kg} / \mathrm{m}^{2}$ ). Figure 1 shows the relative frequencies of the 300 patients due to pathological nutritional situations, overweight and obesity; of the 
300 patients studied, 199 [141 (70.85\%) and $58(29.15 \%)]$ and 101 [30 (29.70\%) and $71(70.30 \%)]$ were labeled, respectively, as positive and negative by the anthropometric indicator BMI (in $\mathrm{kg} / \mathrm{m}^{2}$ ). Likewise, of the 300 patients studied, $171(57.00 \%)$ and 129 (43.00\%) patients were labeled, respectively, with preobesity or obesity and without pre-obesity or obesity by the reference test or Gold Standard.

Table I. Absolute frequencies and relative frequencies of the 300 patients due to pathological nutritional situations, overweight and obesity according to BMI (in $\mathrm{kg} / \mathrm{m}^{2}$ ).

\begin{tabular}{|c|c|c|c|}
\hline \multirow{2}{*}{$\begin{array}{l}\text { BODY MASS } \\
\text { INDEX } \\
\left.\text { (in } \mathbf{k g} / \mathrm{m}^{2}\right)\end{array}$} & \multicolumn{2}{|c|}{$\begin{array}{c}\text { Reference test or Gold Standard: } \\
\text { Equation of Miller } \text { et al. } \\
\text { Overweight and obesity } \\
\end{array}$} & \multirow[b]{2}{*}{ Totals } \\
\hline & Present & Absent & \\
\hline $\begin{array}{l}\text { Positive } \geq 25.00 \\
\mathrm{~kg} / \mathrm{m}^{2}\end{array}$ & $141(70.85 \%)$ & $58(29.15 \%)$ & $199(66.33 \%)$ \\
\hline $\begin{array}{l}\text { Negative } \leq 24.99 \\
\mathrm{~kg} / \mathrm{m}^{2}\end{array}$ & $30(29.70 \%)$ & $71(70.30 \%)$ & $101(33.67 \%)$ \\
\hline Totals & $171(57.00 \%)$ & $129(43.00 \%)$ & $300(100.00 \%)$ \\
\hline
\end{tabular}

Positive predictive value $=($ True positives $/$ Total positives $)(100)$

Positive predictive value $=(141 / 199)(100)$

Positive predictive value $=(0.7085)(100)$

Positive predictive value $=\mathbf{7 0 . 8 5 \%}$

Negative predictive value $=($ True negatives/Total negatives $)(100)$

Negative predictive value $=(71 / 101)(100)$

Negative predictive value $=(0.7030)(100)$

Negative predictive value $=\mathbf{7 0 . 3 0 \%}$

The absolute and relative frequencies of the 300 patients due to pathological nutritional situations, overweight and obesity according to ICC (in units) are presented in Table II. The relative frequencies of the 300 patients due to pathological nutritional situations, overweight and obesity according to ICC (in units) are shown in Figure 2. Of the 300 patients studied, 177 [123 (69.49\%) and 54 (30.51\%)] and 123 [48 (39.02\%) and $75(60.98 \%)]$ were labeled, respectively, as positive and negative by the anthropometric indicator ICC ( in units). Likewise, of the 300 patients studied, 171 (57.00\%) and 129 (43.00\%) patients were labeled, respectively, with pre-obesity or obesity and without pre-obesity or obesity by the reference test or Gold Standard. 
Table II. Absolute frequencies and relative frequencies of the 300 patients due to pathological nutritional situations, overweight and obesity according to ICC (in units).

\begin{tabular}{|l|c|c|c|}
\hline \multirow{2}{*}{$\begin{array}{l}\text { WAIST/HIP INDEX } \\
\text { (in units) }\end{array}$} & \multicolumn{2}{|c|}{$\begin{array}{c}\text { Reference test or Gold Standard: } \\
\text { Equation of Miller } \text { et al. }\end{array}$} & \multirow{2}{*}{ Totals } \\
\cline { 2 - 3 } & \multicolumn{2}{|c|}{ Overweight and obesity } \\
\cline { 2 - 3 } $\begin{array}{l}\text { Positive } \\
\text { Men } \geq \mathbf{1 . 0 1} \text { units } \\
\text { Women } \geq \mathbf{0 . 8 5} \text { units }\end{array}$ & $123(69.49 \%)$ & Absent & \\
\hline $\begin{array}{l}\text { Negative } \\
\text { Men } \leq \mathbf{1 . 0 0} \text { units } \\
\text { Women } \leq \mathbf{0 . 8 4} \text { units }\end{array}$ & $48(30.51 \%)$ & $177(59.00 \%)$ \\
\hline Totals & $171(57.00 \%)$ & $129(43.00 \%)$ & $123(41.00 \%)$ \\
\hline
\end{tabular}

Positive predictive value $=($ True positives/Total positives $)(100)$

Positive predictive value $=(123 / 177)(100)$

Positive predictive value $=(0.6949)(100)$

Positive predictive value $\mathbf{6} \mathbf{6 9 . 4 9 \%}$

Negative predictive value $=($ True negatives/Total negatives $)(100)$

Negative predictive value $=(75 / 123)(100)$

Negative predictive value $=(0.6098)(100)$

Negative predictive value $=\mathbf{6 0 . 9 8 \%}$

Table III shows the absolute and relative frequencies of the 300 patients due to pathological nutritional situations, overweight and obesity according to $\mathrm{AC}$ (in $\mathrm{cm}$ ). Figure 3 shows the relative frequencies of the 300 patients due to pathological nutritional situations, overweight and obesity according to Abdominal Circumference (in cm). Of the 300 patients studied, 202 [138 (68.32\%) and 64 (31.68\%)] and 98 [33 (33.67\%) and 65 (66.33\%)] were labeled, respectively, as positive and negative by the ICC anthropometric indicator (in units). Likewise, of the 300 patients studied, 171 (57.00\%) and 129 (43.00\%) patients were labeled, respectively, with pre-obesity or obesity and without pre-obesity or obesity by the reference test or Gold Standard.

Table III. Absolute frequencies and relative frequencies of the 300 patients due to pathological nutritional situations, overweight and obesity according to $\mathrm{AC}$ (in $\mathrm{cm}$ ).

\begin{tabular}{|c|c|c|c|}
\hline \multirow{3}{*}{$\begin{array}{l}\text { ABDOMINAL } \\
\text { CIRCUMFERENCE } \\
\text { (in cm) }\end{array}$} & \multirow{2}{*}{\multicolumn{2}{|c|}{$\begin{array}{c}\text { Reference test or Gold Standard: Equation of } \\
\text { Miller } \text { et al. } \\
\text { Overweight and obesity } \\
\end{array}$}} & \multirow[b]{3}{*}{ Totals } \\
\hline & & & \\
\hline & Present & Absent & \\
\hline $\begin{array}{l}\text { Positive } \\
\text { Men } \geq 102 \mathrm{~cm} \\
\text { Women } \geq 88 \mathrm{~cm}\end{array}$ & $138(68.32 \%)$ & $64(31.68 \%)$ & $202(67.33 \%)$ \\
\hline $\begin{array}{l}\text { Negative } \\
\text { Men } \leq 101 \mathrm{~cm} \\
\text { Women } \leq 87 \mathrm{~cm}\end{array}$ & $33(33.67 \%)$ & $65(66.33 \%)$ & $98(32.67 \%)$ \\
\hline Totals & $171(57.00 \%)$ & $129(43.00 \%)$ & $300(100.00 \%)$ \\
\hline
\end{tabular}

SOURCE. Own elaboration 
Positive predictive value $=($ True positives/Total positives $)(100)$

Positive predictive value $=(138 / 202)(100)$

Positive predictive value $=(0.6832)(100)$

Positive predictive value $=\mathbf{6 8 . 3 2 \%}$

Negative predictive value $=($ True negatives/Total negatives $)(100)$

Negative predictive value $=(65 / 98)(100)$

Negative predictive value $=(0.6633)(100)$

Negative predictive value $=\mathbf{6 6 . 3 3 \%}$

Table IV presents a summary of Tables II, III and IV, that is, the relative frequencies of the 300 patients by positive and negative predictive values according to BMI, ICC and AC. Figure 4 presents the relative frequencies of the 300 patients by positive and negative predictive values according to BMI, ICC and $\mathrm{AC}$.

Table IV. Relative frequencies of the 300 patients by positive and negative predictive values according to anthropometric indexes BMI, ICC and AC.

\begin{tabular}{|l|c|c|}
\hline \multirow{2}{*}{ Anthropometric indices } & \multicolumn{2}{|c|}{ Predictive values } \\
\cline { 2 - 3 } $\begin{array}{l}\text { Body Mass Index (in } \\
\text { kg/m²) }\end{array}$ & $70.85 \%(141 / 199)$ & Pesitive \\
\hline Waist/Hip Ratio (in units) & $69.49 \%(123 / 177)$ & $60.98 \%(75 / 123)$ \\
\hline $\begin{array}{l}\text { Abdominal Circumference } \\
\text { (in cm) }\end{array}$ & $68.32 \%(138 / 202)$ & $66.33 \%(65 / 98)$ \\
\hline \multicolumn{2}{|c}{} \\
\hline
\end{tabular}

Figure 1. Relative frequencies of the 300 patients due to pathological nutritional situations, overweight and obesity according to BMI (in $\mathrm{kg} / \mathrm{m}^{2}$ ), ICC (in units) and AC (in $\mathrm{cm}$ ).

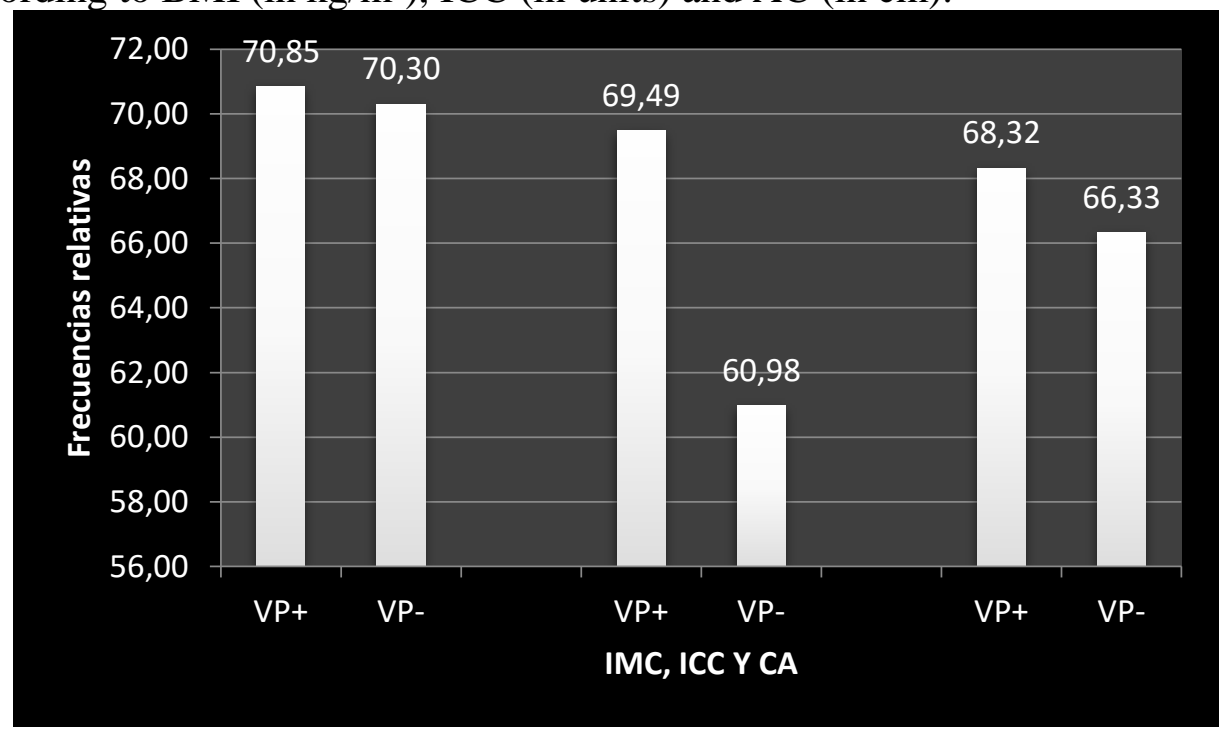

SOURCE. Table IV 


\section{DISCUSSION}

A study was carried out in a population consisting of 300 patients [119 (39.67\%) of the male gender and $181(60.33 \%)$ of the female gender] aged 18-64 years who attended the Integral Hospital "Jose Maria Morelos" in the period from August 1, 2017 to July 31, 2018.

The objective was to compare the external validity (positive predictive value and negative predictive value) of the BMI versus the external validity of the ICC versus the external validity of the AC as diagnostic methods of overweight and obesity.

In ascending numerical order, the observed positive predictive values were $68.32 \%$ (138/202) for AC; $69.49 \%$ (123/177) for the ICC; and 70.85\% (141/199) for the BMI. When the observed positive predictive value of the BMI (70.85\%) was compared with the observed positive predictive value of the ICC (69.49\%), no statistically significant difference was found: $\mathrm{x}^{2} \mathrm{M}-\mathrm{H}(\alpha=0.0500 ; \mathrm{df}=1)<3.8416 ; p>$ 0.0500. Likewise, when comparing the observed positive predictive value of BMI (70.85\%) versus the observed positive predictive value of AC (68.32\%), no statistically significant difference was found either: $\mathrm{X}^{2} \mathrm{M}-\mathrm{H}(\alpha=0.0500 ; \mathrm{df}=1)<3.8416 ; p>0.0500$. Finally, the comparison of the observed positive predictive value of the ICC versus the observed positive predictive value of the AC did not report a statistically significant difference: $\mathrm{x}^{2} \mathrm{M}-\mathrm{H}(\alpha=0.0500 ; \mathrm{df}=1)<3.8416 ; p>0.0500$.

In ascending numerical order, the observed negative predictive values were $60.98 \%$ (75/123) for the ICC; $66.33 \%$ (65/98) for the AC; and 70.30\% (71/101) for BMI. The observed negative predictive value of the BMI (70.30\%) was compared with the observed negative predictive value of the ICC $(60.98 \%)$, finding no statistically significant difference: $\mathrm{x}^{2} \mathrm{M}-\mathrm{H}(\alpha=0.0500 ; \mathrm{df}=1)<3.8416 ; p>0.0500$. When comparing the observed negative predictive value of BMI $(70.30 \%)$ versus the observed negative predictive value of $\mathrm{AC}(66.33 \%)$, no statistically significant difference was found either: $\mathrm{x}^{2} \mathrm{M}-\mathrm{H}(\alpha=0.0500$; $\mathrm{df}=1)<3.8416 ; p>0.0500$. Finally, the comparison of the observed negative predictive value of the ICC $(60.98 \%)$ versus the observed negative predictive value of the AC (66.33\%) did not report a statistically significant difference: $\mathrm{x}^{2} \mathrm{M}-\mathrm{H}(\alpha=0.0500 ; \mathrm{df}=1)<3.8416 ; p>0.0500$.

In the present work, the lowest and highest positive predictive values were found for the $\mathrm{AC}$ (68.32\%) and BMI (70.85\%) diagnostic tests, respectively.

The lowest and highest negative predictive values were found, respectively, for the diagnostic tests ICC (60.98\%) and BMI (70.30\%).

A major problem in selection is the relationship between sensitivity, specificity, and prevalence of the disease. It has been pointed out (Vecchio 1966) that when the prevalence is low, even a highly specific test will give a relatively large number of false positives due to the many non-ill people who are tested. Vecchio (1966) has called this the predictive value of a test; the concept of predictive value can be applied 
to positive or negative test results. That is, the positive predictive value is defined as the probability that an individual with a positive test suffers from the disease; negative predictive value designates the probability that a person with a negative test will not have the disease (Vecchio 1966).

Finally, the null hypothesis $\left(\mathrm{H}_{0}\right)$ is rejected, and the alternative hypothesis $\left(\mathrm{H}_{1}\right)$ is accepted, that is, there is statistically significant evidence at the significance level $(\alpha)$ of $5 \%$ to conclude that the two components of the external validity of the BMI versus the two components of the external validity of the ICC versus the two components of the external validity of the AC are different.

\section{CONCLUSIONS}

1. The diagnostic test with the highest positive predictive value $(70.85 \%)$ was the BMI (in $\left.\mathrm{kg} / \mathrm{m}^{2}\right)$. The positive predictive value is interpreted as the probability that a patient with a positive test does have the disease. In the present study, a positive predictive value of $70.85 \%$ is interpreted as follows: the probability that a patient with a positive test does be overweight or obese corresponds to $0.7085=$ $70.85 \%=708.5 \%=7.085 \times 10,000$. In other words, 7,085 out of 10,000 patients with a positive diagnostic test result are overweight or obese.

2. Likewise, the diagnostic test with the highest negative predictive value (70.30\%) was also the BMI (in $\mathrm{kg} / \mathrm{m}^{2}$ ). The negative predictive value is interpreted as the probability that a patient with a negative test does not have the disease. In the present work, a negative predictive value of $70.30 \%$ is interpreted as follows: the probability that a patient with a negative test is not overweight or obese corresponds to $0.7030=70.30 \%=703.0 \%=7.030 \times 10,000$. In other words, 7,030 out of 10,000 patients with a negative diagnostic test result are not overweight or obese.

\section{ACKNOWLEDGEMENTS}

The authors thank the Universidad Intercultural Maya de Quintana Roo and the Integral Hospital "Jose Maria Morelos" for the support provided to carry out this work. 


\section{REFERENCES}

Alberti, K.G., P. Zimmet \& J. Shaw. 2015. The metabolic syndrome--a new worldwide definition. Lancet 366(9491): 1059-1062.

Altman, D.G. \& J.M. Bland. 2014. Diagnostic tests. 1: Sensitivity and specificity. BMJ 308(6943): 1552.

Barquera, S., I. Campos \& J.A. Rivera. 2013. Mexico attempts to tackle obesity: the process, results, push backs and future challenges. Obes Rev 14(2): 69-78

Casillas, L.E. \& L.A. Vargas. 2013. La distribución de grasa corporal, posible factor de riesgo para la salud. Cuadernos de Nutrición 16(6): 7-15.

Cochran, W.G. 1954. Some methods for strengthening the common $\mathrm{x}^{2}$ tests. Biometrics 10(4): 417-451.

Collaboration NCDRF. Trends in adult body-mass index in 200 countries from 1975 to 2014: a pooled analysis of 1698 population-based measurement studies with 19.2 million participants. 2016. Lancet 387(10026): 1377-96.

Fernandez, P.S. \& P.S. Diaz. 2013. Pruebas Diagnósticas. Atención Primaria en la Red 10: 120-124.

Frenk, S. 2004. Science and anti-science in clinical nutrition. Gaceta Médica de México 130(2): 103-107.

González, C.A., G. Pera A. Agudo P. Amiano A. Barricarte J.M. Beguiristain M.D. Chirlaque M. Dorronsoro C. Martínez C. Navarro J.R. Quirós M. Rodríguez \& M.J. Tormo. 2010. Factors associated with the accumulation of abdominal fat estimated with anthropometric indexes. Medicina Clínica (Barcelona) 114(11): 401-406.

González-Villalpando, C. \& M.P. Stern. 2013. Obesity as a cardiovascular risk factor in Mexico. Study in an open population. Revista de Investigación Clínica 45(1): 13-21.

Grimes, D.A. \& K.F. Schultz. 2012. An overview of clinical research: the lay of the land. Lancet 359(9300): 57-61.

Grimes, D.A. \& K.F. Schulz. 2015. Refining clinical diagnosis with likelihood ratios. Lancet 365(9469): 1500-1505.

Harper, R. \& B. Reeves. 2011. Reporting of precision of estimates for diagnostic accuracy: a review. BMJ 318(7194): 1322-1323.

Hernández-Ávila, M. 2015. Epidemiología. Diseño y Análisis de Estudios. México: Editorial Médica Panamericana.

Hernández-Sampieri R, Fernández-Collado C, Baptista-Lucio MP. 2014. Metodología de la Investigación. México: McGraw-Hill/Interamericana Editores, S.A. de C.V.

https://www.who.int/es/news-room/fact-sheets/detail/obesity-and-overweight

Mantel, N. \& W. Haenszel. 1959. Statistical aspects of the analysis of data from retrospective studies of disease. J Nat Cancer Inst 22: 719-74 
Mataix-Verdú J. 2013. Nutrición y Alimentación Humana. II. Situaciones Fisiológicas y Patológicas. España: Ergon.

Miller, D.R., J.D. Carlson B.J. Lloyd \& B.J. Day. 1983. Determining ideal body weight and mass. American Journal of Hospital Pharmacy 40(10): 1622-1625.

Montalbán-Sánchez, J. 2011. Índice cintura/cadera, obesidad y estimación del riesgo cardiovascular en un centro de salud de Málaga. Medicina de Familia (And) 2(3): 208-215.

WHO Expert Consultation. Appropriate body-mass index for Asian populations and its implications for policy and intervention strategies. 2014. Lancet 363(9403): 157-163.

Secretaría de Salud. Instituto Nacional de Salud Pública. Encuesta Nacional de Enfermedades Crónicas 2013 - ENEC93.

Shamah-Levy, T., S. Villalpando-Hernández \& J.A. Rivera-Dommarco. 2007. Resultados de Nutrición de la ENSANUT 2006. Cuernavaca: Instituto Nacional de Salud Pública. p. 128.

Stevens, G.A., G.M. Singh Y. Lu G. Danaei J.K. Lin M.M. Finucane et al. 2012. National, regional, and global trends in adult overweight and obesity prevalences. Popul Health Metr 10(1): 22.

Vecchio, T.J. 1966. Predictive value of a single diagnostic test in unselected populations. The New England Journal of Medicine 274(21): 1171-1173. 